\title{
Use of photomodeler as a measuring and management tool in construction projects
}

Ali Basha 1, Hossam El-Din Fawzy 2, Magda Farhan 3, Mohammed Sherif 4, ${ }^{*}$, Marco N. Botross 5, Reem Selim 6 , Eman El Sherbini 6, Amira Roshdy 6, Mohammed Reda 6, Rehab Gharib 6, Ahmed El Qazzaz 6, Mohammed Hamdeen 6, Norhan Lotfy 6, Omnia Abdel Galil 6, Esraa Gamal 6, Asmaa Shabaan ${ }^{6}$ and Nourhan Fouda ${ }^{6}$

\footnotetext{
${ }^{1}$ Associate Professor, Civil Engineering Department, Faculty of Engineering, Kafr El-Sheikh University, Egypt.

${ }^{2}$ Professor, Civil Engineering Department, Faculty of Engineering, Kafr El-Sheikh University, Egypt.

${ }^{3}$ Assistant Professor, Civil Engineering Department, Faculty of Engineering, Kafr El-Sheikh University, Egypt.

${ }_{4}^{4}$ Teaching Assistant, Civil Engineering Department, Faculty of Engineering, Kafr El-Sheikh University, Egypt.

${ }^{5}$ Master of science, Civil Engineering Department, Faculty of Engineering, Kafr El-Sheikh University, Egypt.

${ }^{6}$ MSc Student, Civil Engineering Department, Faculty of Engineering, Kafr El-Sheikh University, Egypt.
}

Global Journal of Engineering and Technology Advances, 2022, 10(02), 032-042

Publication history: Received on 07 January 2022; revised on 09 February 2022; accepted on 11 February 2022

Article DOI: https://doi.org/10.30574/gjeta.2022.10.2.0034

\begin{abstract}
Photogrammetry can contribute not only with precision, but especially with speed and efficiency regarding to documentation; it is an ideal system for producing 3D models, for creating data bases, and offering efficient solutions in emergency cases, etc. There are here some examples of the use of digital photogrammetry based on systems and methods which make possible to operate reducing the working time in the site, and operating very light and inexpensive equipment. This system is specially adapted to emergency works and archaeology, when it is needed to work on field without the full support of complete office equipment.
\end{abstract}

Keywords: Close-range photogrammetry; Photomodeler; Digital monitoring system; Construction projects

\section{Introduction}

Construction process is a process during which construction products are being made and includes several subprocesses, which recursively include other sub processes. Construction projects during their accomplishment in the field require much time and expense, and close management control of them is required if they are to be completed within the established time, cost limitations and within prescribed quality [1-9].

The need for surveying and recording the cultural property is increasing every day and is demanding proper answers from experts and scientists. The answer to such a problem must be based in the use of photogrammetry and other new technologies whose use must be widely extended. Experts in such technics are not enough in number for solving the problem. This means that they can't take on their shoulders the responsibility of the complete task. The real problem today for the developing of the use of photogrammetry lies in training the people able to operate those systems: Architects, archeologists, art historians, curators, draftsmen and technicians in general [7, 8 and 9].

The purpose of this study was to compare the accuracy and precision between the Reverse Projection and Photo Modeler methods for suspect height analysis. Thirty analysts were assigned to measure the heights of three different suspects, one for each method, with the suspects having been recorded standing at three different distances in a scene. For Reverse Projection, the analysts were provided with height scales to place and video-record at the same positions their suspects stood in at the test scene, so that frames could be extracted from the video and overlaid onto frames of

\footnotetext{
* Corresponding author: Mohammed Sherif; Email: magdafarhan@yahoo.com

Civil Engineering Department, Faculty of Engineering, Kafr El-Sheikh University, Egypt. 
the suspects to measure height. For Photo Modeler, analysts calibrated frames of the suspects using 3D point cloud data obtained from a laser scan of the scene, so that measurements could be made in Photo Modeler software [1-5].

With rapid development of digital technology, photogrammetry has been coming into digital age. Therefore, automation of interior and relative orientation, digital terrain models is one of the most important tasks in digital photogrammetry. Digital Elevation Models (DEM) is 3D models of a part of surface on the earth. DEMs are used for topographic mapping, engineering and environmental applications, spatial data visualization, and integration into Geographic Information Systems and combined analysis with other data. There are various data sources for DEM. These data sources are generally aerial photographs, satellite images, cartographic maps and measured terrestrial points [7-9].

The derivation of (DEM) from photographs and digital images is one of the main tasks of photogrammetry. The photogrammetric technology may be an appropriate solution for obtaining the DEM of large areas at the present time. DEM data can easily be obtained from stereo images in photogrammetry methods. The manual measurement of DEMs in photogrammetric instruments and digital systems is expensive and time consuming. Therefore, the automation of DEM generation from aerial photography is urgently needed [8].

Automation of the photogrammetric working process is one of the major subjects for image correlation. In order to generate digital elevation models of digitized aerial photographs, the automatic correlation is generally used. Correlation is calculated between a pair of stereo images in digital photogrammetry. The best-fixed points are identified. Root Mean Square Errors (RMS) for elevations describe the accuracy of the produced DEM. RMS's are calculated by differences between field elevations of points and elevations that are obtained from points of DEM by interpolation [35].

Project conditions such as technical complexity, importance of timely completion, resource limitations, and substantial costs put great emphasis on the planning, scheduling, and control of construction operations. Unfortunately, the construction process, once it is set into motion, is not a self-regulating mechanism and requires expert guidance if events are to conform to plans. In order to function professionally in today's construction project, one must be able to recognize and diagnose problems as they evolve and apply the appropriate principles in order to avoid or resolve these problems [4-9].

The Digital Close Range Photogrammetry (DCRP), is a technology that has testified an unremitting evolution in recent years, it shows the importance of using (DCRP) in many different applications and fields. DCRP is based mainly on digital technology at storing and manipulating data (images) within the applied field, in order to create digital models that correspond to the real captured objectives. That opens up the possibility of terms standard modeling in such (length, area, and size as well as spatial coordinates). There is no doubt that digital modeling works by multiple mathematical models-based software, such: Interactive digital stereo systems, PHIDIAS, I Witness, Image Modeler and Photo Modeler [4-8].

Application fields of the Digital Close Range Photogrammetry (DCRP) technique:

- Monitoring of the structural deformations

- Roads geometrical designs

- Geological and morphological researches

- Crime scene reconstruction

- Sanitary engineering

- Heritage documentation

The Digital Close Range Photogrammetry (DCRP), also used in A new design of soil erosion and rainfall simulator is presented at study as an attempt to deduce a mathematical formula of soil surface erosion phenomenon to describe the behavior of the sandy soil under the rainfall simulation, soil deformation such as the gullies and surface eroding rills are monitored by the Digital Close Range Photogrammetry (DCRP) technique that includes capturing digital images by a smart cellphone camera, and a Terrestrial Laser Scanner (TLS) to digitalize the soil surface as a point cloud data to produce Digital Elevation Models (DEM) with an accuracy reaches $0.10 \mathrm{~mm}$ with the watershed, color relief, 3D surface model. The results show that the mentioned methods give a typical digital surface feature express especially of using geometrical adjustment that controls the orientation of the digital surface. The SIFT technology of the digital imaging feature detection achieves accurate results despite its small cost, $12 \%$ if compared to the TLS method. As a result of the statistical observations, a simple mathematical formula was generated through the DCRP technique that describes the sandy soil behavior under a hybrid technique of rainfall simulation as a relation between the eroding rate and the duration through the different gradient slopes $[8,9]$. 
Photo Modeler software is one of the most famous photogrammetric software packages, indicated to it by many previous studies, used a variety of versions in the procedure for modeling the studied objects. Photo Modeler is mainly based on two mathematical theories, Direct Linear Transformation (DLT) and Scale Invariant Feature Transform (SIFT) to calculate the camera parameters by a calibration process, and creating a dense surface model respectively.

\section{Photogrammetry}

The formal definition of photogrammetry is the art, science, and technology of obtaining reliable information about physical objects and the environment through the process of recording, measuring, and interpreting photographic images and patterns of electromagnetic radiant energy and other phenomena. In many instances, the use of photogrammetry can be more efficient, less labor-intensive, and more cost-effective than other types of field 3D data collection, resulting in products that have a level of detail, accuracy, range, and price that is difficult to match with other technologies (Birch 2006). As described previously, the main component necessary for a photogrammetric project is a series of overlapping stereoscopic images. The stereo images may be captured by a large variety of cameras at almost any height or platform (from tripod to earth-orbiting satellite).

Photogrammetry is used in fields such as topographic mapping, architecture, engineering, manufacturing, quality control, police investigation, cultural heritage, and geology. Archaeologists use it to quickly produce plans of large or complex sites, and meteorologists use it to determine the wind speed of tornados when objective weather data cannot be obtained.

\subsection{Digital camera calibration}

Camera calibration is the process of determining the internal characteristics, and the camera intrinsic parameters, so it can be used as a measurement device (Semi-metric camera).

Applied mathematical model of CCP (Distortion Eq.s):

$d x_{\mathrm{i}}=\left(\mathrm{X}_{\mathrm{i}}-\mathrm{X}_{o}\right)\left(k_{1} r^{2}+k_{2} r^{4}+k_{3} r^{6}\right)+P_{1}\left(r^{2}+2\left(\mathrm{X}_{\mathrm{i}}-\mathrm{X}_{0}\right)^{2}\right)+2 P_{2}\left(\mathrm{X}_{\mathrm{i}}-\mathrm{X}_{0}\right)\left(Y_{\mathrm{i}}-Y_{0}\right)+V x_{\mathrm{i}}$

$d y_{\mathrm{i}}=\left(Y_{\mathrm{i}}-Y_{o}\right)\left(k_{1} r^{2}+k_{2} r^{4}+k_{3} r^{6}\right)+2 P_{1}\left(\mathrm{X}_{\mathrm{i}}-\mathrm{X}_{0}\right)\left(Y_{\mathrm{i}}-Y_{0}\right)+P_{2}\left(r^{2}+2\left(Y_{\mathrm{i}}-Y_{0}\right)^{2}\right)+V y_{\mathrm{i}}$

Where

$d x \mathrm{i}, d y \mathrm{i}$ are image refinement components in $x$ and $y$ coordinates,

$\mathrm{Xi}, Y \mathrm{i}$ are the captured $\mathrm{CP} i$ world coordinates according to $X, Y$ coordinate system,

$k_{1}, k_{2}, k_{3}$ are the three symmetrical parameters of the radial distortion,

$P_{1}, P_{2}$ are the tangential distortion asymmetrical parameters,

$r$ is the magnitude of the radial vector length from the point of symmetry to the observed CP point on the imaging system.

$r_{\mathrm{i}}=\sqrt{\left(\mathrm{X}_{\mathrm{i}}-\mathrm{X}_{0}\right)^{2}+\left(Y_{\mathrm{i}}-Y_{0}\right)^{2}}$

$\mathrm{X} o, Y o$ are the camera station world coordinates in $\mathrm{X}, Y$ axes, $V x \mathrm{i}, V y$ i are the RMS residual error in $X, Y$ directions.

General Direct Linear Transform (DLT) applied equations 


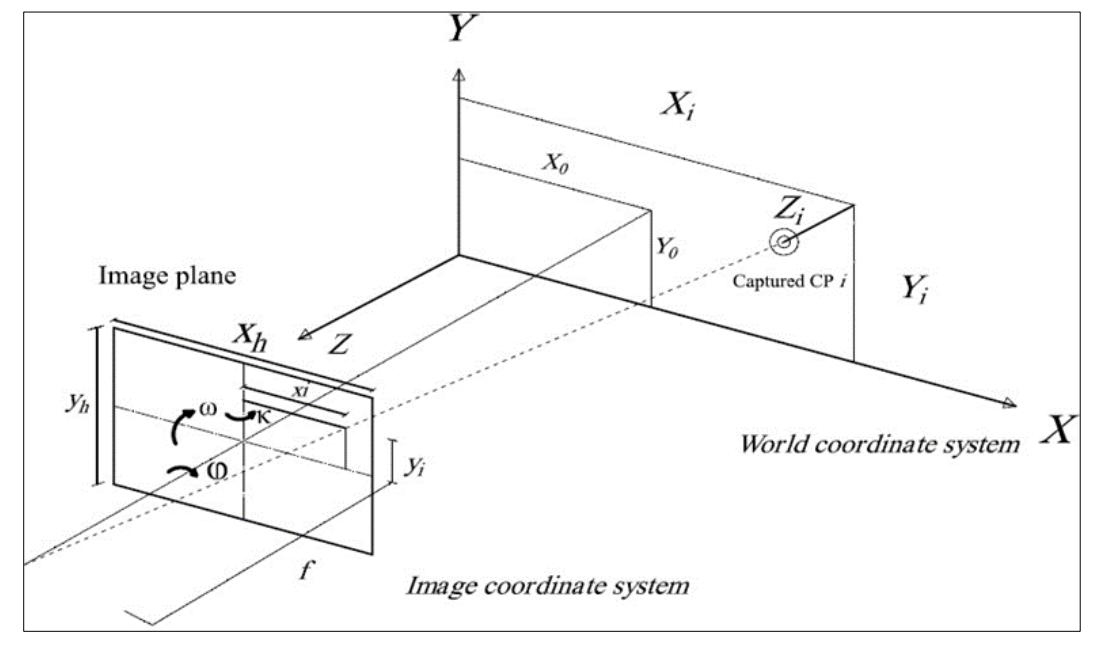

Figure 1 Geometrical application of the DLT model

$\mathrm{X}_{\mathrm{i}}+\mathrm{dx} \mathrm{X}_{\mathrm{i}}+\mathrm{V}_{\mathrm{xi}}=\frac{\mathrm{L} 1 \mathrm{X} 1+L 2 Y 2+L 3 Z 1+L 4}{\mathrm{~L} 9 \mathrm{X} 1+L 10 Y 1+L 11 Z 1+1}$

$Y_{i}+d y_{i}+V_{y i}=\frac{L 5 X 1+L 6 Y 1+L 7 Z 1+L 8}{L 9 X 1+L 10 Y 1+L 11 Z 1+1}$

Where

(XY,and Z): are the object space coordinates of that point.

$\left(D x i, d y_{i}\right)$ : are image refinement components in $\mathrm{x}$ and $\mathrm{y}$ to account for thenonlinear components of lens distortions.

(Vxi ,Vyi): represent the small random errors in the measured comparator coordinates (residual errors).

$L_{1} \ldots \ldots . . . . L_{11}:$ The transformation coefficients can be expressed in a matrix form as:

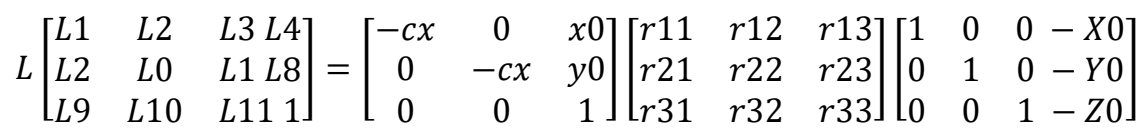

Camera intrinsic parameters: (f) the camera focal length, (Fw) Camera format of the width and (Fh) Camera format of the height.

$\omega, \varphi, k$ are the magnitude of the rotation angles of the image position (outer orientation).

\section{Methodology}

\subsection{Camera matching method}

Reverse Projection and Camera Matching are two common methods that allow users to obtain measurements from a single frame of video or a photograph. These methods vary in their robustness, flexibility and ease of execution and can all be proven useful when applied correctly. The variations in these methods are mainly dependent on several factors such as

- The availability of the camera.

- Scene preservation.

- Quality of the overall image (i.e. how clearly the items can be discerned).

- The change in camera position or movement (Panning cameras, mobile phones, body worn cameras and in-car cameras are all considered moving cameras and are rarely fixed and stationary). 
- The presence of a sufficient number of common features between the captured video and the scene in its current state.

The items above define the overall quality of the available video/photographic evidence and when considered in their totality, should provide the analyst with a set of standards by which they can determine the method most likely to provide a successful solution. In some cases where the quality of evidence is poor, the analyst must simply accept that a solution is not attainable, or the accuracy of results may not be sufficient. However, when the quality of evidence is good, a method that employs a true mathematically sound photogrammetric solution should be at the top of the hierarchy. As the quality of evidence diminishes, the need for a more flexible solution must be employed at the expense of introduction of subjectivity. However, this does not diminish the effectiveness of the technique or method, but instead tells the analyst that they must consider how and which possible errors could affect their analysis.

\subsection{Camera calibration}

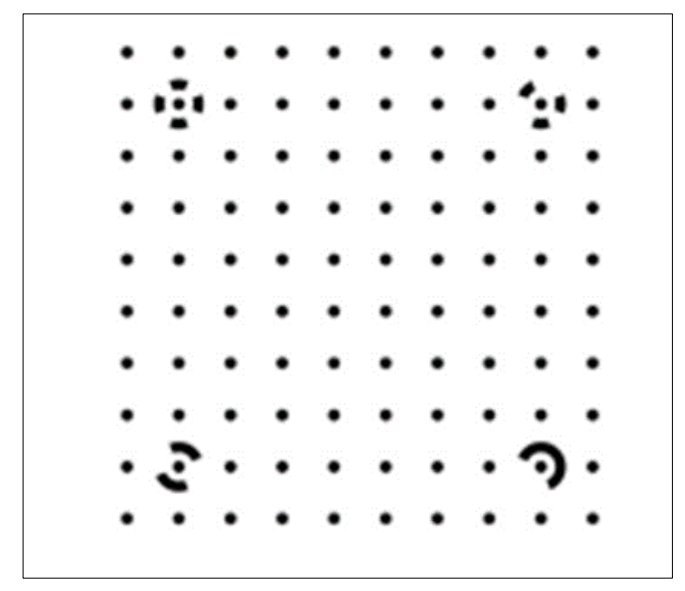

Figure 2 Camera Calibration Sheet Model

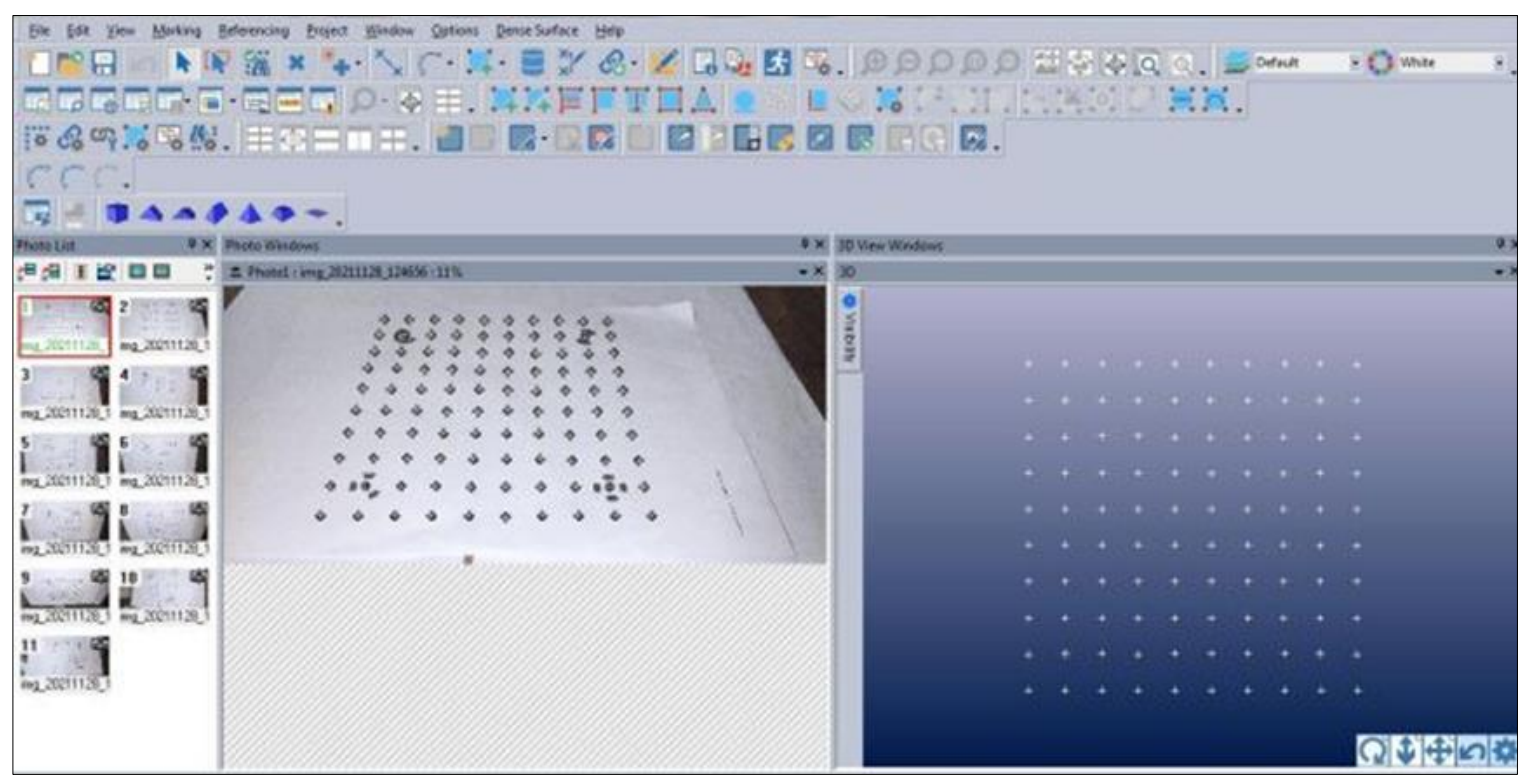

Figure 3 Digital camera calibration projects

By using a single calibration sheet printed on an A4 paper with 4 control points, one of them will be considered as principle point $(0,0,0)$, it is noticed that all points at the sheet have $\mathrm{Z}=0$ and $\mathrm{X} \& \mathrm{Y}$ values differenced in a constant determined values, known by the software. Three pictures captured in $(0,90,180)$ degree rolling around the orientation of the camera lens of each side of the sheet. So the total captured pictures $=12$ (this number of images is enough to 
determine the lens unknown distortion values (d1, d2, e1, e2 and the camera format size). By using Photo Modeler calibration pane, 12 calibration sheet images were loaded into the software to be analyzed. One of the most important calibration results is "the camera format size". This pattern will be calculated manually to be compared with software calibration result.

\begin{tabular}{|l|l|}
\hline & \\
\hline Calibration type & Calibrator \\
\hline Focal length (mm) & 5.39 \\
Image size (pixels) & $4624 \times 2134$ \\
\hline Format size $(\mathrm{mm})$ & $7.21 \times 3.29$ \\
\hline Principal point (mm) & $3.51 \times 1.62$ \\
\hline Lens distortion (K) & $\mathrm{K} 1[-0.00207] \mathrm{K} 2[0.000219] \mathrm{K} 3[0]$ \\
\hline Lens distortion (P) & $\mathrm{P} 1[0.000336] \mathrm{P} 2[-0.00028]$ \\
Quality - Residuals & $\mathrm{RMS}[0.243]$ Max[0.959] \\
Quality - Coverage & 50 \\
Multispectral & $\mathrm{No}$ \\
\hline
\end{tabular}

Figure 4 Results of the calibration project

\subsection{Field measurements}

The project below aims to measure the quantity of the sandy soil surface by digital close-range photogrammetry

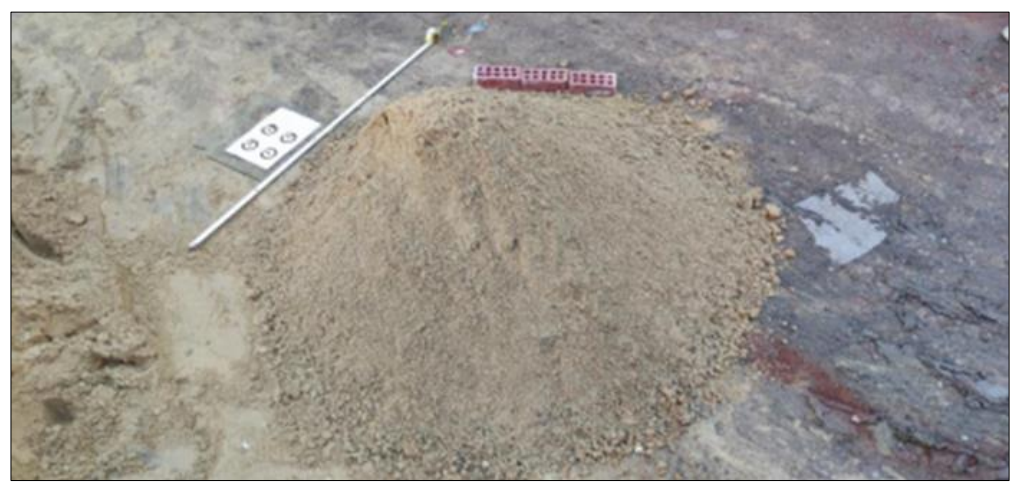

Figure 5 Soil sample

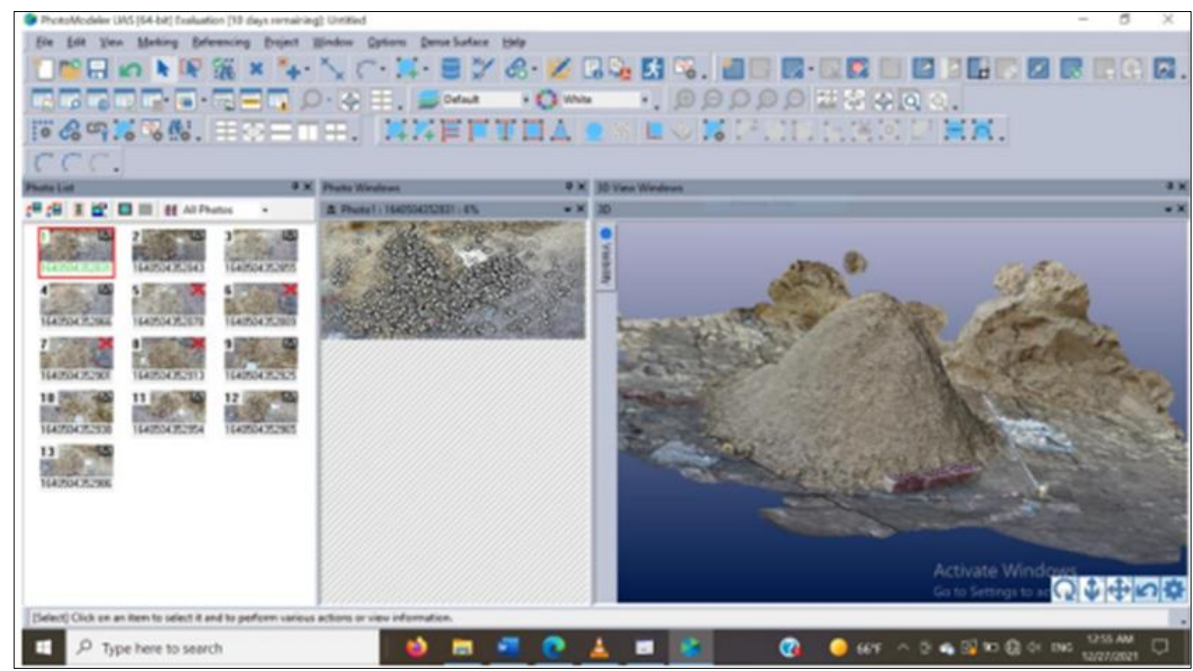

Figure 6 Soil sample in photo modeler 


\subsection{Proposed scale distance}

Two points from code target are used as a scale distance $=9.5 \mathrm{~cm}$ and two points $\mathrm{x} 1=30.00 \mathrm{~cm}, \mathrm{x} 2=60.00 \mathrm{~cm}$ from the ruler are used as a scale distance $=30.00 \mathrm{~cm}$ with the project to calculate the total mass volume of the sand

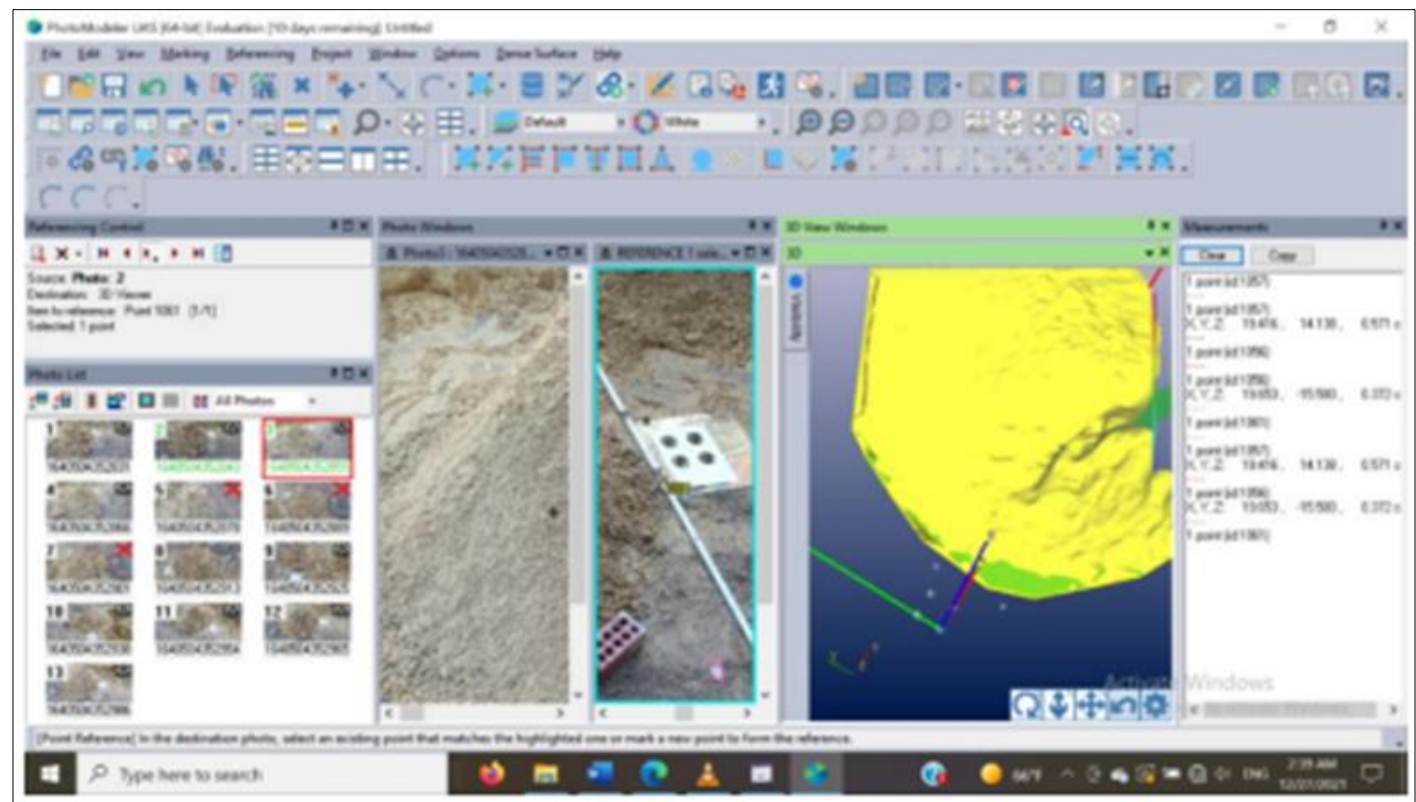

Figure 7 Scale factor determination

\subsection{Measurements, Precisions values, and the comparative values}

Volume above plane: $342362.451 \mathrm{~cm} 3$

Calibrated volume: $352118.668 \mathrm{~cm} 3$

Error percentage value $=2.77$ about $3.00 \%$

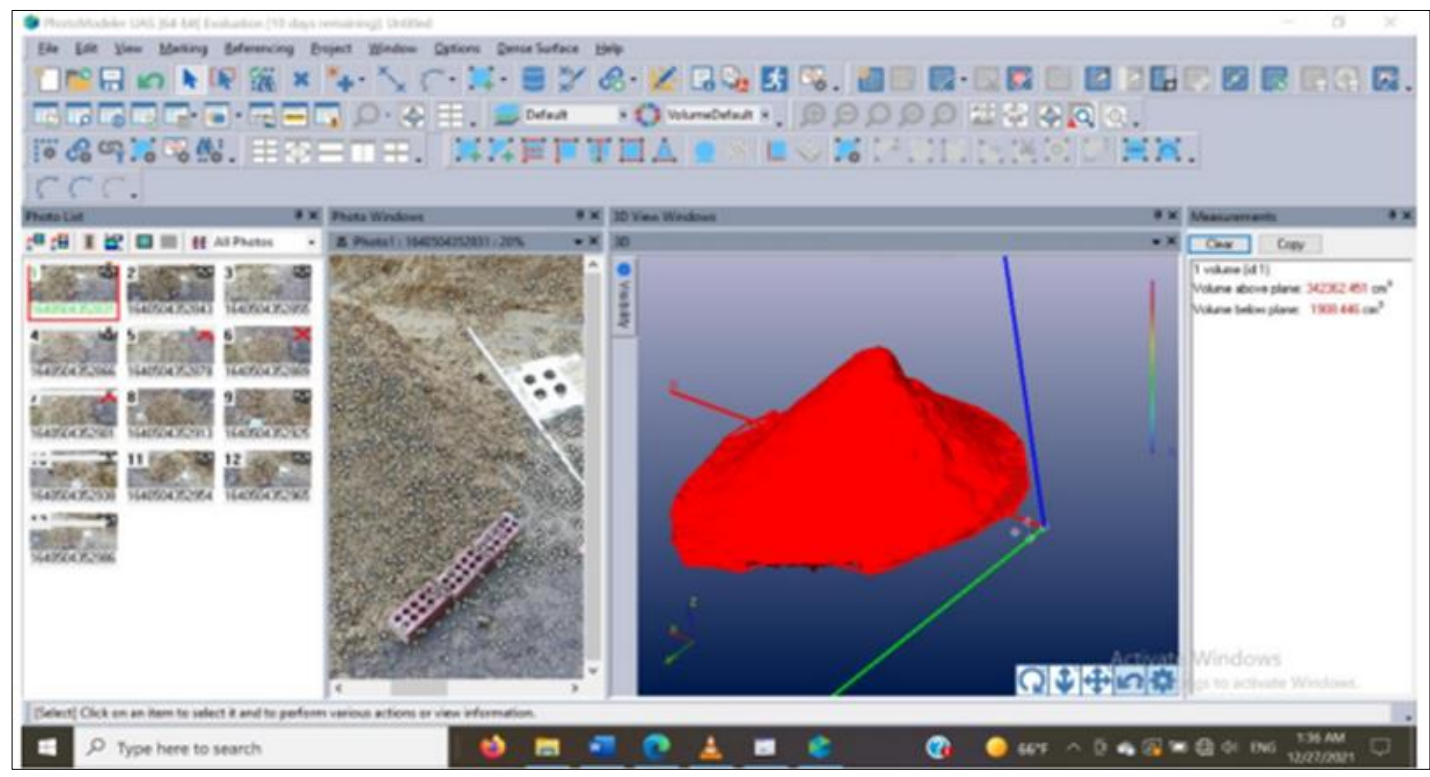

Figure 8 Volume quantification with code target 


\section{Results}

Comparison of error rates according to type of camera, number of photos for each project and other factors that affect the accuracy of the measurement process:

Table 1 Quantity measurement

\begin{tabular}{|c|c|c|c|c|c|}
\hline Type of camera & megapixel & $\begin{array}{l}\text { No. of } \\
\text { photos }\end{array}$ & $\begin{array}{l}\text { Distance between } \\
\text { camera and target }(\mathrm{m})\end{array}$ & $\begin{array}{l}\text { Connectivity } \\
\text { angle }\end{array}$ & $\begin{array}{l}\text { Error } \\
\text { percentage }\end{array}$ \\
\hline $\mathrm{Sm}-\mathrm{N} 10 \mathrm{f}(4.32)$ & 32 & 13 & 2.0 & $30^{\circ}$ & $2.77 \%$ \\
\hline $\mathrm{Sm}-\mathrm{A} 10 \mathrm{f}(3.61)$ & 13 & 24 & 3.0 & $15^{0}$ & $8.20 \%$ \\
\hline Sm - A71 f (5.23) & 64 & 19 & 2.0 & $20^{\circ}$ & $3.13 \%$ \\
\hline Sm - M31 f (5.23) & 16 & 14 & 2.0 & $30^{\circ}$ & $6.18 \%$ \\
\hline Sm - A10 f (3.61) & 13 & 21 & 2.5 & $20^{\circ}$ & $6.63 \%$ \\
\hline IPhone XS Max (4.25) & 12 & 14 & 3.0 & $45^{0}$ & $4.54 \%$ \\
\hline IPhone XS Max (4.25) & 12 & 12 & 3.0 & $45^{0}$ & $4.83 \%$ \\
\hline $\mathrm{Sm}-\mathrm{N} 10 \mathrm{f}(4.32)$ & 32 & 10 & 3.0 & $60^{\circ}$ & $4.78 \%$ \\
\hline MI Note 10 (5.43) & 48 & 14 & 3.0 & $30^{\circ}$ & $4.45 \%$ \\
\hline MI Note 10 (5.43) & 48 & 26 & 1.0 & $20^{\circ}$ & $2.93 \%$ \\
\hline IPhone XS Max (4.25) & 12 & 14 & 2.5 & $45^{0}$ & $4.32 \%$ \\
\hline Redmi - N10 pro max & 32 & 12 & 3.5 & $30^{\circ}$ & $5.62 \%$ \\
\hline Oppo A1k (3.61) & 8 & 12 & 3.0 & $30^{\circ}$ & $7.34 \%$ \\
\hline Oppo A1k (3.61) & 8 & 11 & 3.0 & $45^{0}$ & $7.74 \%$ \\
\hline Oppo A1k (3.61) & 8 & 14 & 2.0 & $30^{\circ}$ & $6.29 \%$ \\
\hline
\end{tabular}

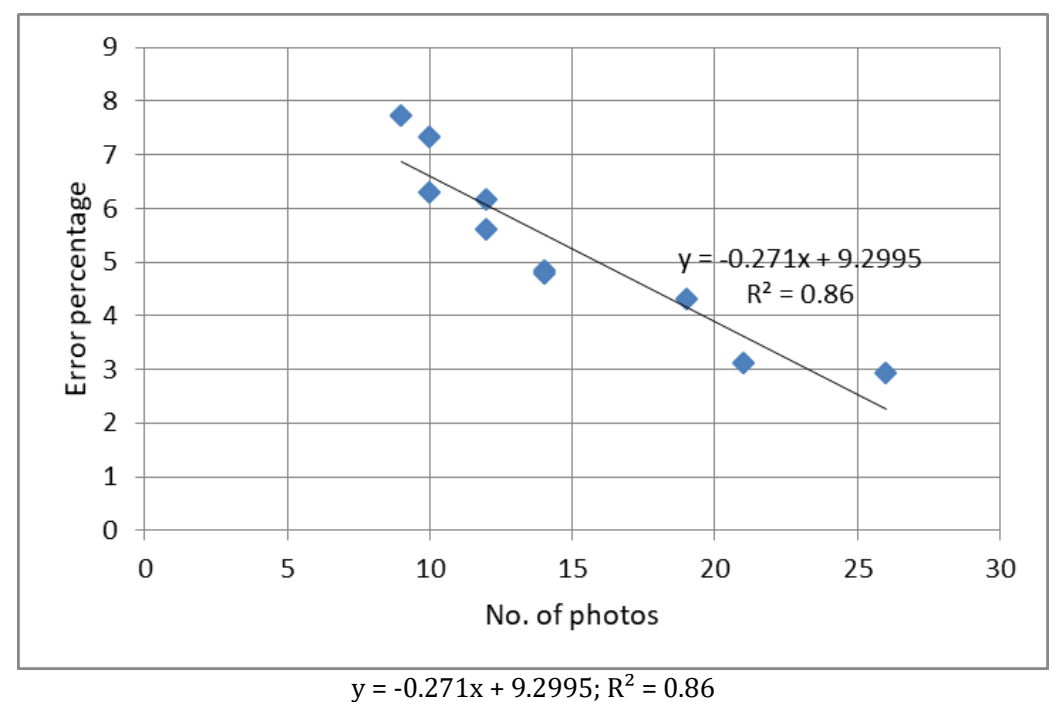

Figure 9 Errors percentage related to number of photos for each photomodeler project 
Table 2 Linear measurement

\begin{tabular}{|l|c|c|c|c|c|}
\hline Type of camera & megapixel & $\begin{array}{l}\text { No. of } \\
\text { photos }\end{array}$ & $\begin{array}{l}\text { Distance between } \\
\text { camera and target }\end{array}$ & $\begin{array}{l}\text { Connectivity } \\
\text { angle }\end{array}$ & $\begin{array}{l}\text { Error } \\
\text { percentage }\end{array}$ \\
\hline Sm - A52 f (5.23) & 64 & 3 & 8.0 & $45^{\circ}$ & $1.04 \%$ \\
\hline Sm - N8 f (4.32) & 12 & 2 & 1.0 & $20^{\circ}$ & $1.87 \%$ \\
\hline MI Note 10 (5.43) & 48 & 5 & 3.0 & $30^{\circ}$ & $1.58 \%$ \\
\hline
\end{tabular}

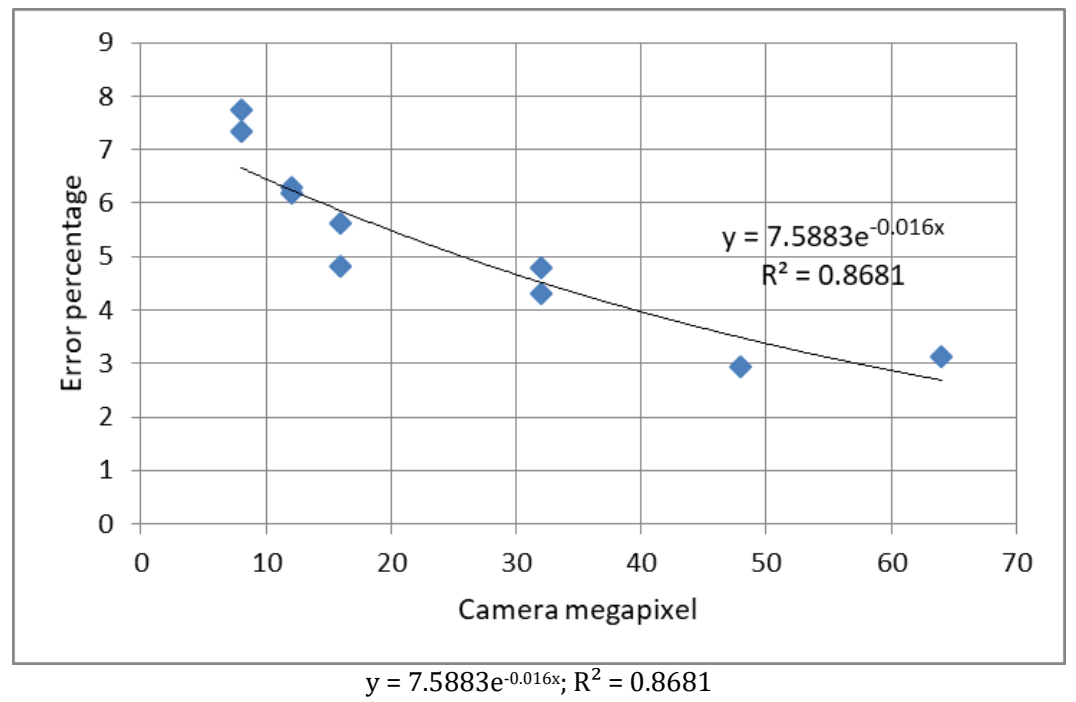

Figure 10 Errors percentage related to camera megapixel

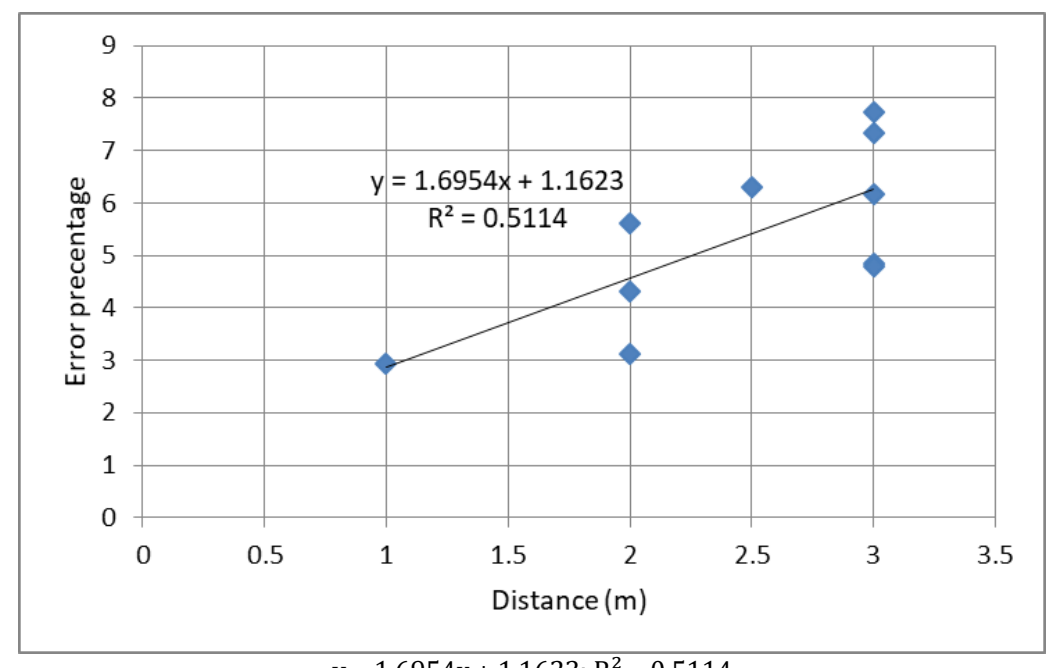

Figure 11 Errors percentage related to distance between camera and target

\section{Discussion}

The purpose of this comparison is to determine the extent to which different factors affect the error rate resulting from the program, such as the type and quality of the camera used in the measurement process.The higher the quality of the camera used, the higher the efficiency of the images captured for the target and the lower the error rate resulting from the program. As well as the number of captured images of the target as it increased, this led to the position of the target to form a dense surface for the measurement process with a lower error rate. 
There are many other factors that must be taken into account to reduce the error rate resulting from the program, including:

- Natural lighting, where the more shooting is in the daytime mode, the greater the clarity of the target to conduct the measurement process with higher accuracy.

- The distance between the camera and the target, the smaller the distance, the greater the accuracy of the measurement and the lower the error rate generated by the software.

- For the program, the more the camera calibration was done by a set of points distributed over an area equal to the target project, the better the accuracy.

- The scale of the image, or the scale used in the measurement and monitoring operations, the more the scale used is compatible with the observed distance, the lower the error rate in the monitoring due to the nonrepetition of the unit of measurement when calculating the total length of the distance

\section{Conclusion}

The use of photogrammetry as a measurement technique for different purposes is a very effective, fast, cheap and safe method, especially it has the ability to survey and observe targets without physical contact. With the widespread use of computer software based on mathematical theories, it became easy for technical specialists to use this new technology to measure quantify various engineering purposes.

Photo Modeler software was one of the most commonly used computer applications in previous studies for test-field measurements and 3D projects creation such, soil erosion quantification, crime or accident scene reconstruction, observations of structural elements deformation, gridded Digital Elevation Model (DEM) generation, and many other application fields due to its ability to create robust contrasted coded targets, small-large-single-multi metric calibration sheets, and analyze any type of digital cameras images in varied format in addition to manipulate and processes digital images to extract results in few minutes.

This study shows through the proposed experiments the efficiency of use Photo Modeler as a measuring tool, as with any measuring technique, it has a percentage of residual error, so the Photo Modeler measurement accuracy and reliability reach in general 95\% at least estimation for various engineering quantification purposes such size, length, digital nonmetric camera calibration and monitoring of points coordinates, as that percentage able to be increased by adjusting the manual procedures through some simple cautions during project formation by taking more photos with close range angles and using good type of digital cameras.

\section{Compliance with ethical standards}

\section{Acknowledgments}

The authors wish to acknowledge the support of Surveying Laboratory Staff, Faculty of Engineering, Kafrelsheikh University, Egypt, in providing the enabling environment for carrying out the research.

\section{Disclosure of conflict of interest}

The authors declared no potential conflicts of interest concerning the research, authorship, and/or publication of this article.

\section{References}

[1] Ordóñez C, Riveiro B, Arias P, Armesto J. Application of Close Range Photogrammetry to Deck Measurement in Recreational Ships. Sensors (Basel, Switzerland), [online]. 2009; 9(9): 6991-7002.

[2] Gruen A. DTM Generation and Visualization, Symposium on Digital Photogrammetry. V-1 V-16, Istanbul. 1998.

[3] Jachimski J. Video Stereo Digitizer. A small digital stereophotogrammetric working station for the needs of sit and other applications, Geodesy, Photogrammetry and Monitoring of Environment (Chosen Problems), Geodezja. 1995; 38: 71-93.

[4] El-Din Fawzy H. Study the accuracy of digital close range photogrammetry technique software as a measuring tool. Alexandria Engineering Journal, [online]. 2019; 58(1): 171-179. 
[5] Liscio E, Guryn H, Le Q, Olver A. A comparison of reverse projection and PhotoModeler for suspect height analysis. Forensic Science International. 2021; 320: 110690.

[6] S Robson Luhmann, S Kyle, I Harley. Close Range Photogrammetry Principles, Techniques and Applications, Whittles Publishing. 2011.

[7] El-Nimr, Maher T, Basha, Ali M, Abo-Raya, Mohamed M, Zakaria, Mohamed H. General deformation behavior of deep excavation support systems: A review. Global Journal of Engineering and Technology Advances. 2022; 10(01): 039-057.

[8] El-Din Fawzy, H., Basha, A. M., \& Botross, M. N. (2020). Estimating a mathematical formula of soil erosion under the effect of rainfall simulation by digital close range photogrammetry technique. Alexandria Engineering Journal. doi:10.1016/j.aej.2020.09.039

[9] El-Din Fawzy, H. (2019). Study the accuracy of digital close range photogrammetry technique software as a measuring tool. Alexandria Engineering Journal, 58(1), 171-179. doi:10.1016/j.aej.2018.04.004 